\title{
Prevalence and correlates of HIV testing among adolescents $10-19$ years in a post-conflict pastoralist community of Karamoja region, Uganda
}

Rogers N. Ssebunya ${ }^{\text {*}^{*}}$, Rhoda K. Wanyenze ${ }^{2}$, Leticia Namale, Heather Lukolyo ${ }^{1}$, Grace P. Kisitu', Patricia Nahirya-Ntege ${ }^{1}$ and Adeodata Kekitiinwa ${ }^{1}$

\begin{abstract}
Background: Adolescents are a priority group in HIV prevention and treatment. This study sought to determine the prevalence and correlates of HIV testing services (HTS) among adolescents in the pastoralist post-conflict area of Karamoja sub region, Uganda.

Methods: A cross sectional study of 1439 adolescents aged 10-19 years, attending nine public health facilities in five of the seven districts of Karamoja, was conducted between August to September 2016. Adolescents were consecutively selected and interviewed using structured interviewer administered questionnaires. All respondents who had never tested for HIV were offered HTS. The main outcome was ever tested for HIV. Correlates of ever tested were analysed using multivariate logistic regression model.

Results: Of the 1439 adolescents, 904 (62.8\%) were females, 1203 (83.6\%) were aged 15-19 years, 618 (43.0\%) had attained primary education and 885 (61.5\%) had ever had sex. Overall 1177 (81.8\%) had ever tested and received HIV results. Older age (15-19 years) (adj.OR $=2.71,95 \%$ Cl: 1.85-3.96), secondary level education or higher (adj.OR $=2.33$, 95\% Cl: 1.33-4.10), and ever had sex (adj.OR $=2.03,95 \% \mathrm{Cl}: 1.42-2.90$ ) were associated with higher odds of HIV testing. Of the 262 who had never tested, 169 (64.5\%) accepted testing and 2.4\% were HIV positive. Reasons for not accepting the test included fear of being tested and not ready for an HIV test because of perceived suffering HIV positive clients go through.

Conclusion: Awareness of HIV status and uptake of HTS among adolescents in this hard-to-reach post-conflict region was high and close to the global UNAIDS target of $90 \%$. However, the HIV prevalence of $2.4 \%$ among the non-testers who accepted to be tested was high and emphasises the need for targeted testing to reach the undiagnosed HIV infected adolescents in this region.
\end{abstract}

Keywords: Adolescents, HIV, HIV testing services, Uganda, Pastoralist communities

\footnotetext{
* Correspondence: ssebunyarogers@gmail.com; rssebunya@baylor-uganda.org

${ }^{1}$ Baylor College of Medicine Children's Foundation, Mulago Hospital

Complex, P.O. Box 72052, Clock Tower, Kampala, Uganda

Full list of author information is available at the end of the article
}

C The Author(s). 2018 Open Access This article is distributed under the terms of the Creative Commons Attribution 4.0 International License (http://creativecommons.org/licenses/by/4.0/), which permits unrestricted use, distribution, and reproduction in any medium, provided you give appropriate credit to the original author(s) and the source, provide a link to the Creative Commons license, and indicate if changes were made. The Creative Commons Public Domain Dedication waiver (http://creativecommons.org/publicdomain/zero/1.0/) applies to the data made available in this article, unless otherwise stated. 


\section{Background}

Adolescents and young people are a critical focus population in HIV prevention and treatment and particularly important in the attainment of the global targets towards elimination of HIV/AIDS by 2030. According to the 2016 UNICEF data, 670,000 out of 2.1 million (31.9\%) new infections by 2015 were among young people aged 15-24 years - these included 250,000 infections among adolescents 15-19 years [1, 2]. New HIV infections among adolescents in sub Saharan Africa are not declining as quickly as among other age groups [3]. Adolescent females and young women aged 15-24 years are at a higher risk of HIV infection, contributing $25 \%$ of all new infections among adults in sub-Saharan Africa in 2015 [4]. Similar trends have been documented regarding AIDS-related mortality especially in sub-Saharan Africa where access to HIV testing, care and treatment services by young people is still a challenge [2, 3]. Every hour, 26 adolescents get infected, with close to 2 million living with HIV worldwide. This is compounded by low HIVrelated knowledge-only $26 \%$ of the girls and $32 \%$ of the boys 15-19 years in sub-Saharan Africa know how HIV is transmitted and how it can be prevented [5]. Adolescents in hard to reach post-conflict and pastoralist communities where access to health care services including HIV testing services is limited are probably more disadvantaged. Such settings have also been linked to increased vulnerability to HIV and high-risk sexual behaviours [6-9].

Prevention of HIV transmission and acquisition among adolescents amidst multiple challenges including peer pressure, sense of invincibility and physiological changes calls for multi-dimensional interventions. HIV testing is a window for all HIV related care and treatment services and an essential step in achieving "the UNAIDS 90-90-90 targets". However, globally only $35 \%$ of young people were aware of their HIV status in 2015 [10]. In sub-Saharan Africa, only $13 \%$ of the female and 9\% of the male adolescents had ever tested for HIV and received their results in the last 12 months [1].

Awareness of HIV status and uptake of HIV Testing Services (HTS) varies considerably across different settings [11-13]. In a study in Malawi, HTS uptake ranged from $16.9 \%$ among the poor to $25.4 \%$ among individuals in the higher wealth quartile [14] while elsewhere uptake ranged from $27 \%$ to over $76.5 \%$ [15-18]. In Uganda, overall uptake of HTS among adolescents is less than $20 \%$, however the reasons behind this low uptake are not well documented. Determinants of HTS uptake include age, education level, and willingness to disclose HIV results $[19,20]$. Despite the variability in testing coverage, there is limited documentation of HIV prevalence and uptake of HTS among adolescents 10-19 years in remote, pastoralist, or post-conflict settings. A few of the studies that have elicited HTS uptake in post conflict communities in Uganda were among a small sample of youths $15-35$ years [21], among children and adolescents (0-18 years) receiving mental health care services [22], and among refugees $\geq 20$ years [23]. In a survey conducted in 2016 in Karamoja, HTS uptake among young people was $61.7 \%$ [24], however, the determinants of uptake were not highlighted. Additionally an understanding of the influence of contextual issues on HTS uptake for example; cultural transitions from isolation and fear from cattle raids to stability, urbanisation, and increased HIV/AIDS awareness provides an impetus for this study. The study therefore aimed to determine the prevalence and correlates of HIV testing among adolescents 10-19 years receiving primary health care services in a pastoralist and post-conflict region of Karamoja in Uganda. Adolescents who had never tested were offered HTS and the uptake as well as the reasons for refusal to test documented.

\section{Methods \\ Study setting and population}

Karamoja sub-region is located in the north eastern part of Uganda and is occupied by a pastoralist community that is dependent on animals for survival and security. In this setting, males do much of the animal rearing while females do the housework. This society has over the years had conflicts with other tribal neighbourhoods fighting for land, water and animals, a practice that has of recent stabilised when the government initiated a disarmament program and provided other logistical and humanitarian support in terms of food, shelter, health care and education. According to the 2011 Uganda AIDS indicator survey, general population HIV prevalence in Karamoja was 3.5\% [25] - prevalence among female adolescents $15-24$ years was $3.5 \%$ compared to $2.6 \%$ in their male peers [26]. The UNICEF annual report of 2013 showed Karamoja lagging behind compared to western Uganda and Acholi regions regarding access to HTS and antiretroviral therapy (ART) for prevention of mother to child transmission (PMTCT) [27].

\section{Study design, sample size and sampling}

This was a cross-sectional survey involving 1439 adolescents (10-19 years) receiving primary health care services at the outpatient department (OPD) and maternal child health $(\mathrm{MCH})$ clinics at public health facilities between August to September 2016. Bennett's sample size formula [28] was used considering health facilities as the clusters and expected daily number of adolescents attending the facilities estimated at 140 . Since the coverage of HIV testing among adolescents in this region was not known at the time of planning this study, a conservative prevalence of $50 \%$ and a design effect of 2.0 were used 
to yield a minimum sample size of 1375 participants from nine clusters. The highest volume facilities within the region-facilities that contributed $80 \%$ of all OPD attendance for adolescents in the previous year were sampled. The $80 \%$ mark was chosen to allow adequate representation of the districts and facilities within the region to be included in the study. The 9 facilities were located in five of the seven districts in the sub-region. The number of adolescents to be interviewed at each of these nine facilities was then determined using probability proportional to size (PPS), based on the numbers of adolescents who sought HTS in the prior quarter (April-June 2016) before data collection. Within each facility, adolescents were consecutively sampled until the required number per facility was obtained. All adolescents were approached for participation irrespective of their reason for coming to the facility.

\section{Data collection procedures}

Ethical approval for this study was obtained from Makerere University School of Biomedical Sciences Higher Degree Research and Ethics Committee (SBSREC) and the Uganda National Council for Science and Technology (UNCST) before data collection. Additionally, permission was sought from district and health facility heads. After the selection, adolescents were screened for eligibility. Written informed parental or guardian consent and assent were obtained from adolescents $<18$ years while those $\geq 18$ years consented before enrolment into the study. Adolescents $<18$ years who came to these facilities without a guardian or parent were advised to come back with a parent/guardian who could consent on their behalf. Parents/guardians and the adolescents were informed that the study included an assessment of knowledge and access to HIV services and that some would be offered an HIV test and tested if they accepted to do so. Respondents were interviewed by trained research assistants using semi-structure questionnaires and a modified HIV knowledge tool. All respondents were asked if they had ever tested for HIV and received their results. Those who had never tested where asked if they would like to be tested for HIV. Those who accepted were linked to the HTS sites within the health facilities.

Based on the institutional policies, all research assistants signed a confidentiality agreement before data collection to ensure confidentiality of respondent's results. Those who refused to test for HIV were asked for the reasons, and these were documented through open ended questions. All questionnaires were checked by field supervisors, for quality control. On a daily basis, the completed questionnaires were collected by a regional supervisor who kept them locked in an office. Data was entered into an access database, cleaned from spreadsheets. The reasons for refusal to test for HIV among those who had never tested were also coded and entered into the database. Clean data was exported to Stata statistical software version 13.0 for analysis.

\section{Variables measurements}

Data collected included; adolescents' socio-demographic characteristics, HIV testing and receipt of results, knowledge of HIV prevention and transmission, knowledge of partner's HIV status, engagement in high-risk sexual behaviours, history of having children, ever had sex, and use of substances or drugs. The main outcome in this study was "ever tested" for HIV which was coded as 1 for "Yes" and 0 for "No". Independent variables included; socio-demographic characteristics like sex, age group, marital status, HIV knowledge ( $\mathrm{Yes}=1, \mathrm{No}=0)$, engaging in high-risk sexual behaviours ( $\mathrm{Yes}=1, \mathrm{No}=0$ ), and use of drugs or other illicit substances (Yes $=1$, No $=0)$. Sex was coded as $($ Female $=1$, Male $=0)$, Age group coded as (15-19 years $=1$ and 10-14 years $=0)$, Ever had sex coded as (Yes $=1$, No $=0)$, Education level coded as (Nursery $=0$, Primary $=1, \geq$ secondary $=2$ ). During testing for significant covariates; marital status was coded as; Never married $=0$, Married/Cohabiting $=1$ and Divorced $/$ Separated $=2$. HIV sero-status of their most recent partner was coded as (Yes $=1, \mathrm{No}=0$ ), while the number of children was coded as (None $=0,1-3=1$ ). The HIV knowledge score was based on an aggregate score obtained by using a KQ-18 HIV questionnaire [29] modified to suit the cultural context for the study population. In line with other literature that considered mean and median scores for cut-off scores [30], participants in our study who scored above or equal to the median score of 11 were considered to have adequate HIV knowledge. Adolescents were considered to have engaged in high-risk sexual behaviours if they inconsistently used a condom and either had multiple sexual partners (two or more sexual partners) or having engaged in transactional sex in the last 6 months.

\section{Statistical analysis}

Descriptive statistics for ever tested were presented as frequencies and percentages. A chi-square test was used to elicit associations between individual characteristics with HIV testing. Odds ratios were generated using a multivariate logistic regression model to elicit associations with HIV testing. We adjusted for a number of variables to include; sex of the adolescent, highest level of education attained, ever had sex, HIV knowledge, number of children the adolescent has ever had, knowing the HIV status of their sexual partners and high-risk sexual behaviours. We excluded marital status as an independent variable in the final model because of potential multi-collinearity with "ever had sex". Variables with a $p$-value of 0.2 and below at bivariate analysis were 
entered into the multivariate models. Model parsimony was ensured by using the backward stepwise modelling and the likelihood ratio test between the full and restricted models. The model that yielded the highest variability in explaining the predicted variable (ever tested) was considered as the best fit. All analyses were conducted using STATA v.13 (College Station, TX).

\section{Results}

\section{Baseline characteristics of study respondents}

Overall, 1481 adolescents were approached for participation and 1443 (97.4\%) were enrolled-four had incomplete data for key variables including the outcome variable and were excluded from analysis. Demographic and baseline characteristics of study respondents are summarized in Table 1 . The majority of adolescents (904, 62.8\%) were females, aged 15-19 years $(1203,83.6 \%)$ and were married or cohabiting $(526,36.6 \%)$. The median age of study participants was 18.0 (iqr $=3$ ) for both males and females. More than half of the adolescents $(737,51.2 \%)$ were in school and nearly $82 \%$ (1177) of the adolescents

Table 1 Baseline characteristics of study respondents

\begin{tabular}{|c|c|c|c|}
\hline Variable, $N=1439$ & & $\mathrm{~N}$ & Percent (\%) \\
\hline \multirow[t]{2}{*}{ Age } & $10-14$ & 236 & 16.4 \\
\hline & $15-19$ & 1203 & 83.6 \\
\hline \multirow[t]{2}{*}{ Sex } & Males & 535 & 37.2 \\
\hline & Females & 904 & 62.8 \\
\hline \multirow[t]{3}{*}{ Marital status } & Never married & 901 & 62.6 \\
\hline & Married/cohabiting & 526 & 36.6 \\
\hline & Divorced/Separated & 12 & 0.8 \\
\hline \multirow[t]{3}{*}{$\begin{array}{l}\text { Highest level } \\
\text { of education }\end{array}$} & $\begin{array}{l}\text { No education \& } \\
\text { Nursery/ECD }\end{array}$ & 354 & 24.6 \\
\hline & Primary/ABEK ${ }^{a}$ & 618 & 43.0 \\
\hline & $\geq$ Secondary & 467 & 32.5 \\
\hline \multirow[t]{3}{*}{ Occupation } & Student/Pupil & 737 & 51.2 \\
\hline & Cattle keeper & 83 & 5.8 \\
\hline & Other \& None & 619 & 43.0 \\
\hline \multirow[t]{2}{*}{ Ever had children } & None & 1079 & 75.0 \\
\hline & 1-3 children & 360 & 25.0 \\
\hline \multirow[t]{2}{*}{ Ever tested for HIV } & Yes & 1177 & 81.8 \\
\hline & No & 262 & 18.2 \\
\hline \multirow{2}{*}{$\begin{array}{l}\text { Uptake of HTS, } \\
n=262\end{array}$} & Yes & 169 & 64.5 \\
\hline & No & 93 & 35.5 \\
\hline \multirow[t]{2}{*}{ HIV prevalence } & Positive & 4 & 2.4 \\
\hline & Negative & 165 & 97.6 \\
\hline \multirow{2}{*}{$\begin{array}{l}\text { Use of drugs/ } \\
\text { Substances }\end{array}$} & Yes & 20 & 1.4 \\
\hline & No & 1419 & 98.6 \\
\hline
\end{tabular}

${ }^{\mathrm{a}}$ ABEK Alternative Basic Education for Karamoja, ECD Early Childhood Development had ever tested for HIV and received results by the time of the interview, of whom nine $(0.8 \%)$ were positive. Of the 262 adolescents who had never tested for HIV, 169 (64.5\%) accepted testing, of whom four (2.4\%) were HIV positive. Thus overall, 13 of the 1346 adolescents who tested (1.0\%) were HIV positive. Figure 1 shows key reasons why adolescents who had never tested refused to test. Among the 93 adolescents who declined testing, for the largest percentage $(n=25,36.2 \%)$ did not offer any specific reason-they just did not want to test. Others feared testing $(n=17,24.6 \%)$ and perceived testing to be painful $(n=7,7.3 \%)$ or did not feel ready for the test ( $n=13,18.8 \%)$. Of the 71 sexually active adolescents who declined an HIV test, only 2 (2.8\%) had engaged in highrisk sexual behaviors. A small proportion (1.4\%) of adolescents reported to have ever used drugs or substances like marijuana, kuber and tobacco smoking.

\section{Adolescent characteristics by HIV testing status}

Results in Table 2 show that a much higher percentage of older adolescents 15-19 years (1051, 89.3\%) ever tested for HIV and received results compared to their younger counterparts $(126,10.7 \%)$. Results further indicate that equal proportions (49.3\% vs $50.7 \%$ ) had ever tested for HIV among those with and without adequate HIV knowledge. A stratified analysis among sexually active adolescents $(n=885), 85(9.6 \%)$ had never been tested for HIV. Additionally, of the 301 adolescents who never knew the sero-status of their most recent sexual partners, 60 (19.9\%) had never tested for HIV. Of the 101 adolescents who engaged in high-risk sexual behaviours, 15 (14.9\%) had never tested for HIV.

\section{Correlates for ever tested among adolescents}

Table 3 highlights three statistically significant associations with HIV testing among adolescents i.e. age of the adolescent, level of education and ever had sex. Older adolescents aged 15-19 years had higher odds (adj.OR $=2.71,95 \%$ CI: $1.85,3.96)$ of HIV testing compared to their younger counterparts aged 10-14 years. Attaining secondary or higher level of education was associated with increased odds of HIV testing compared to those who had no education at all; (adj.OR $=2.33,95 \%$ CI: $1.33,4.10$ ). Additionally adolescents who had ever had sex were more likely to have been tested compared to those that had never; (adj.OR $=2.03$, $95 \%$ CI: 1.42, 2.90). Further still, having adequate level of HIV knowledge, sex, and the parity of the adolescents i.e. whether they have ever had children or not, and engagement in high-risk sexual behaviours were not statistically significant contributors to ever been tested for HIV.

\section{Discussion}

This cross-sectional study aimed to assess the prevalence and correlates of HIV testing among adolescents 


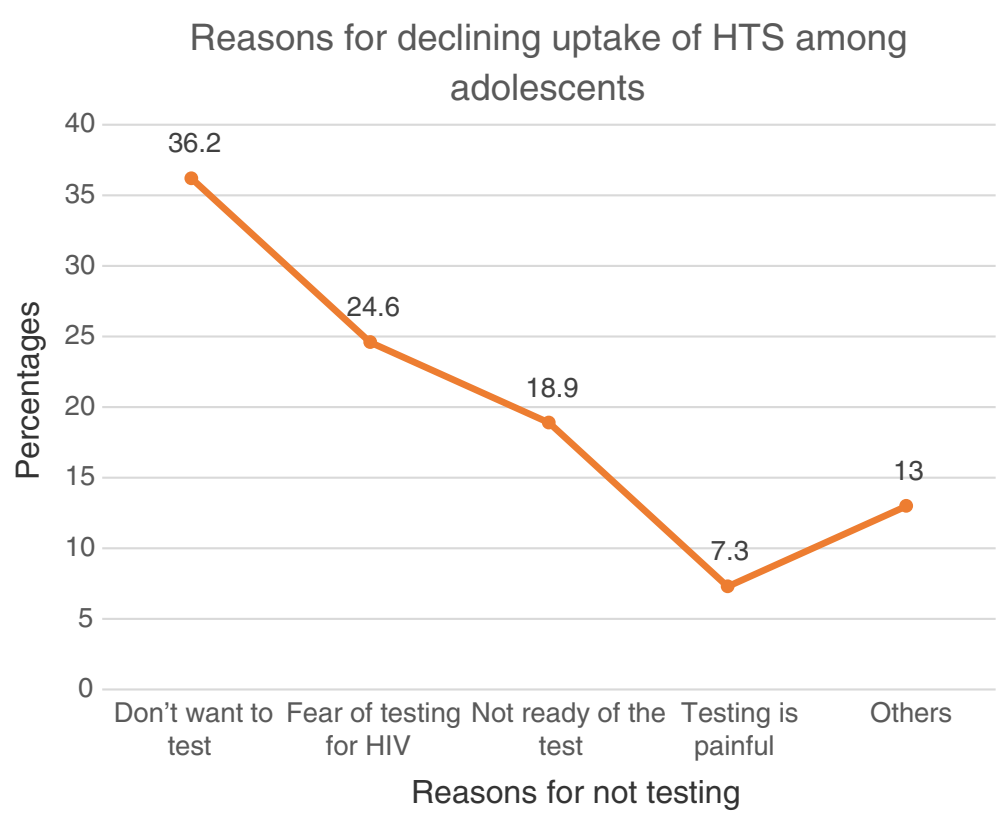

Fig. 1 Reasons for declining taking an HIV test among adolescents 10-19 years

in a post-conflict, pastoralist setting. Over $80 \%$ of the adolescents had ever tested prior to the survey, close to the UNAIDS 90\% target. Overall HIV prevalence among adolescents who tested before and during the study was $1.0 \%$ - which is lower than the national HIV prevalence among young males 15-24 years (1.9\%) and females (3.8\%) [31]. However, among those who had previously not tested, the prevalence was $2.4 \%$ although these numbers were small, this highlights the need for targeted adolescent services to reach the

Table 2 Relationship between HIV testing and individual characteristics of adolescents

\begin{tabular}{|c|c|c|c|c|}
\hline \multirow[t]{2}{*}{ Variable } & & \multicolumn{2}{|l|}{ Ever tested } & \multirow[t]{2}{*}{$p$-value } \\
\hline & & Yes, $n=1177$ & No, $n=262$ & \\
\hline \multirow[t]{2}{*}{ Sex } & Male & $414(35.2)$ & $121(46.2)$ & $0.001^{*}$ \\
\hline & Female & $763(64.8)$ & $141(53.8)$ & \\
\hline \multirow[t]{2}{*}{ Age group } & $10-14$ & $126(10.7)$ & $110(42.0)$ & $0.001^{*}$ \\
\hline & $15-19$ & $1051(89.3)$ & $152(58.0)$ & \\
\hline \multirow[t]{2}{*}{ Adequate HIV knowledge } & Yes & $580(49.3)$ & $91(34.7)$ & $0.001^{*}$ \\
\hline & No & $597(50.7)$ & $171(65.3)$ & \\
\hline \multirow[t]{3}{*}{ Education status } & No Education/Nursery & $288(24.5)$ & $66(25.2)$ & $0.001^{*}$ \\
\hline & Primary/ECD & 466 (39.6) & $152(58.0)$ & \\
\hline & $\geq$ Secondary & $423(35.9)$ & $44(16.8)$ & \\
\hline \multirow[t]{2}{*}{ Ever had sex } & No & $377(32.0)$ & $177(67.6)$ & $0.001^{*}$ \\
\hline & Yes & $800(68.0)$ & $85(32.4)$ & \\
\hline \multirow[t]{2}{*}{ Use of drugs or substances } & No & $1158(98.4)$ & $261(99.6)$ & 0.123 \\
\hline & Yes & $19(1.6)$ & $1(0.4)$ & \\
\hline \multirow[t]{2}{*}{ Knows partners sero-status ${ }^{a}$} & Yes & 559 (69.9) & $25(29.4)$ & $0.001^{*}$ \\
\hline & No & $241(30.1)$ & $60(70.6)$ & \\
\hline \multirow[t]{2}{*}{ High-risk sexual behaviours $^{a}$} & Yes & $86(10.8)$ & $15(17.7)$ & 0.057 \\
\hline & No & $714(89.2)$ & $70(82.3)$ & \\
\hline
\end{tabular}

${ }^{\mathrm{a} A m o n g}$ those who have ever had sex $(n=885)$

*significance at $p<0.05$ 
Table 3 Correlates of Ever tested for HIV among study respondents

\begin{tabular}{|c|c|c|c|c|c|c|c|c|}
\hline Variable & & Ever tested, $n=1177$ & Percent (\%) & Unadj.OR & $95 \% \mathrm{Cl}$ & adj.OR & $95 \% \mathrm{Cl}$ & $p$-value \\
\hline \multirow[t]{2}{*}{ Sex } & Male & 414 & 35.2 & 1.0 (ref) & & & & \\
\hline & Female & 763 & 64.8 & 1.58 & $1.21-2.07$ & 1.23 & $0.89-1.71$ & 0.217 \\
\hline \multirow[t]{2}{*}{ Age group } & $10-14$ & 126 & 10.7 & 1.0 (ref) & & & & \\
\hline & $15-19$ & 1051 & 89.3 & 6.04 & $4.44-8.21$ & 2.71 & $1.85-3.96$ & $0.001^{*}$ \\
\hline \multirow[t]{2}{*}{ Adequate HIV knowledge } & No & 597 & 50.7 & 1.0 (ref) & & & & \\
\hline & Yes & 580 & 49.3 & 1.83 & $1.38-2.41$ & 1.33 & $0.98-1.81$ & 0.07 \\
\hline \multirow[t]{3}{*}{ Education status } & No Education/ Nursery & 288 & 24.5 & 1.0 (ref) & & & & \\
\hline & Primary/ ECD & 466 & 39.6 & 0.70 & $0.51-0.97$ & 1.14 & $0.91-2.20$ & 0.126 \\
\hline & $\geq$ Secondary & 423 & 35.9 & 2.20 & $1.46-3.32$ & 2.33 & $1.33-4.10$ & $0.003^{*}$ \\
\hline \multirow[t]{2}{*}{ Ever had Sex } & No & 377 & 32.0 & 1.0 (ref) & & & & \\
\hline & Yes & 800 & 68.0 & 4.42 & $3.32-5.88$ & 2.03 & $1.42-2.90$ & $0.001^{*}$ \\
\hline \multirow[t]{2}{*}{ Use of drugs or substances } & No & 1158 & 98.4 & 1.0 (ref) & & & & \\
\hline & Yes & 19 & 1.6 & 4.28 & $0.57-32.1$ & 2.19 & $0.27-17.4$ & 0.460 \\
\hline
\end{tabular}

*Significance at $p<0.05$

remaining undiagnosed HIV infections as we approach the first $90 \%$ target.

Our study shows much higher HIV testing among adolescents than the 2016 Uganda demographic health survey (UDHS) [32] and in other studies elsewhere [21, 33]. This community was ravaged by tribal conflicts for over a decade, however, the post-conflict phase and stability led to prioritization of the region and more focused interventions from development partners and implementers, which may explain the much higher coverage and uptake of testing among adolescents in this region [34]. However, despite the high uptake, there is need to sustain these efforts given the significant proportion of adolescents who tested positive among those who had never tested.

Age, level of education, and ever had sex were significantly associated with higher levels of HIV testing. Older adolescents aged 15-19 years had higher odds of HIV testing. In this setting, older adolescents especially boys, take on the role of warriors and looking after cattle and are thus more mobile and probably more likely to access health services. Older adolescents also have more autonomy and decision making powers including health seeking and are also more likely to be sexually active due to the culture of early marriages in this community. This trend has also been documented in other studies $[18,35]$ and highlights the need to mitigate the barriers in accessing HIV testing services in the younger age groups. Whereas the younger adolescents may not be sexually active yet, they should also be targeted for testing given the potential for perinatally transmitted HIV infection [36, 37].

Adolescents who have ever had sex were more likely to have tested for HIV than those who had not. This result could indicate a higher desire among sexually active adolescents to know their sero-status following sexual exposure or prior to sexual encounters. Evidence shows a higher likelihood of HIV testing among individuals who have been exposed to risk behaviors including unprotected sexual encounters and sexually transmitted infections [38-40]. This finding also underscores the need to also target adolescents who have never had any sexual encounter but could be infected due to perinatal exposure.

It is not surprising that adolescents with higher education were more likely to have been tested for HIV since several service providers offer HTS outreaches and door-to-door HIV testing in communities including schools [41, 42].

The high level of stigma towards HIV/AIDS that has been reported in this setting may explain the $>30 \%$ refusal to test among adolescents who had never tested [21, 43]. Adolescent tailored communication strategies including mitigating of stigma in conflict and mobile communities could increase uptake of HIV services.

\section{Limitations}

Our study had several limitations. First the study was facility based and thus excluded those that might have barriers to accessing health facilities in general-this could over-estimate the uptake of HIV testing. Secondly adolescents who tested early in their life but remained sexually active with partners of unknown HIV status were not retested in this study. Finally, adolescents whose guardians did not consent were excludedhowever this was a very small number $(<12)$ among the thousands interviewed and could thus not have significantly influenced the findings. We recommend further research to explore mechanisms of enhancing efficiency for HTS by improving the targeting of HIV testing to adolescents at high risk of HIV infection. 


\section{Conclusion}

Awareness of HIV status and uptake of HTS among adolescents in this hard-to-reach post-conflict pastoralist region was high and close to the global UNAIDS target of the first 90. However, the HIV prevalence of $2.4 \%$ among those that had never tested and accepted to be tested highlights the need for targeted and risk-based testing to reach the undiagnosed HIV-infected adolescents.

\section{Abbreviations}

ANC: Antenatal care; HIV: Human immunodeficiency virus; HTS: HIV testing Services; MCH: Maternal Child Health; OPD: Out Patient Department; SMC: Safe Medical male circumcision; UNAIDS: Joint United Nations Programme on HIV/AIDS

\section{Acknowledgements}

Special and heartfelt thanks to Joseph Kayizzi and Nelson Mugume who ensured that data collection is carried out as per protocol and Henry Balwa who ensure the study has all the necessary regulatory requirements. Additional thanks to UNICEF for the support of the Karamoja project implemented by Baylor-Uganda within which we obtained data to write this paper. I also affirm that all the listed authors have contributed significantly to the work in this manuscript.

\section{Availability of data and materials}

The datasets used and/or analysed during the current study are available from the corresponding author on reasonable request.

\section{Authors' contributions}

Contributed to the study design: RNS, GPK, AK. Analysed the data and wrote first draft: RNS. Contributed to the analysis and interpretation of the data: RKW. Contributed to writing of the paper and all revisions: HL, RKW, LN, GPK, PNN and AK. All authors read and approved the final manuscript.

\section{Ethics approval and consent to participate}

This study received institutional review board clearance from the Makerere University School of Biomedical science Higher Research and Ethics Committee (SBSREC) and Uganda National Council for Science and Technology (UNCST). All respondents provided informed consent and assent before enrolment into the study.

\section{Competing interests}

The authors declare that they have no competing interests.

\section{Publisher's Note}

Springer Nature remains neutral with regard to jurisdictional claims in published maps and institutional affiliations.

\section{Author details}

'Baylor College of Medicine Children's Foundation, Mulago Hospital Complex, P.O. Box 72052, Clock Tower, Kampala, Uganda. ${ }^{2}$ School of Public Health, Makerere University, College of Health Sciences, Kampala, Uganda.

Received: 17 October 2017 Accepted: 4 May 2018

Published online: 10 May 2018

\section{References}

1. UNICEF. Turning the tide against AIDS will require more concentrated focus on adolescents and young people. 2016, Available at: https://data.unicef org/topic/hivaids/adolescents-young-people/. Accessed 22 June 2017.

2. UNAIDS, AIDS by the numbers. 2016, Available at: http://www.unaids.org/ sites/default/files/media_asset/AIDS-by-the-numbers-2016_en.pdf. Accessed 26 June 2017

3. UNAIDS, All in to end adolescent AIDS. 2015, Available at: http://www. unaids.org/sites/default/files/media_asset/20150217_ALL_IN_brochure.pdf. Accessed on 27 June 2017.
4. UNAIDS, Global AIDS update 2016, Available at: http://www.unaids.org/sites/ default/files/media_asset/global-AIDS-update-2016_en.pdf. Accessed on 24 June 2017.

5. UNAIDS and UNICEF. All in to end Adolescent AIDS epidemic, progress report. Available at: http://www.unaids.org/sites/default/files/media_asset/ ALLIN2016ProgressReport en.pdf. Accessed on 22 June 2017.

6. UNICEF, Impact of conflict. 2005. Available at: https://www.unicef.org/ emerg/files/Impact_conflict_women.pdf. Accessed on 20 June 2017.

7. Muhwezi WW, Kinyanda E, Mungherera M, Onyango P, Ngabirano E, Muron J, et al. Vulnerability to high risk sexual behaviour (HRSB) following exposure to war trauma as seen in post-conflict communities in eastern Uganda: a qualitative study. Confl Heal. 2011;5(1):22.

8. Atwood KA, Kennedy SB, Babu EM, Nagbe W, Seekey W, Sirleaf P, et al. Transactional sex among youths in post-conflict Liberia. J Health Popul Nutr. 2011;29(2):113-22

9. UNFPA, Adolescent girls in disaster \& conflict: interventions for improving access to sexual and reproductive health services 2016. Available at: http://www.unfpa.org/sites/default/files/pub-pdf/UNFPA-Adolescent_Girls_ in_Disaster_Conflict-Web.pdf. Accessed on 3 July 2017.

10. UNAIDS, How AIDS changed everything-MDG6: 15 years, 15 lessons of hope from the AIDS response. 2015. Available at: http://www.unaids.org/ sites/default/files/media_asset/MDG6Report_en.pdf. Accessed 16 June 2017.

11. Mafigiri R, Matovu JKB, Makumbi FE, Ndyanabo A, Nabukalu D, Sakor M, et al. HIV prevalence and uptake of HIV/AIDS services among youths (15-24 years) in fishing and neighboring communities of Kasensero, Rakai District, south western Uganda. BMC Public Health. 2017;17(1):251.

12. Swenson RR, Rizzo CJ, Brown LK, Payne N, DiClemente RJ, Salazar LF, et al. Prevalence and correlates of HIV testing among sexually active African American adolescents in four U.S. cities. Sex Transm Dis. 2009;36(9):584-91.

13. Musumari PM, Tangmunkongvorakul A, Srithanaviboonchai $K$, Yungyuankul $S$, Techasrivichien T, Suguimoto SP, et al. Prevalence and correlates of HIV testing among young people enrolled in non-formal education centers in urban Chiang Mai, Thailand: a cross-sectional study. PLoS One. 2016;11(4):e0153452.

14. Helleringer S, Kohler HP, Frimpong JA, Mkandawire J, et al. J Acquir Immune Defic Syndr. 2009;51(2):185-93.

15. Khawcharoenporn T, Chunloy K, Apisarnthanarak A. Uptake of HIV testing and counseling, risk perception and linkage to HIV care among Thai university students. BMC Public Health. 2016;16(1):556.

16. Center KE, Gunn JKL, Asaolu IO, Gibson SJ, Ehiri JE. Contraceptive use and uptake of HIV-testing among sub-Saharan African women. PLoS One. 2016;11(4):e0154213.

17. Govindasamy D, Ferrand RA, Wilmore SM, Ford N, Ahmed S, Afnan-Holmes H, et al. Uptake and yield of HIV testing and counselling among children and adolescents in sub-Saharan Africa: a systematic review. J Int AIDS Soc. 2015:18(1):20182

18. Asaolu IO, Gunn JK, Center KE, Koss MP, Lwelunmor Jl, Ehiri JE. Predictors of HIV testing among youth in sub-Saharan Africa: a cross-sectional study. PLoS One. 2016;11(10):e0164052.

19. Madiba S, Mokgatle M. "Students want HIV testing in schools" a formative evaluation of the acceptability of HIV testing and counselling at schools in Gauteng and north west provinces in South Africa. BMC Public Health. 2015:15:388.

20. Bodika SM, Lekone PE, Loeto P, Alwano MG, Zulu TC, Kim E, et al. Prevalence of HIV testing and counseling and associated factors among secondary school students in Botswana. Int J Adolesc Med Health. 2016;28:149.

21. Kitara DL, Aloyo J. HIV/AIDS stigmatization, the reason for poor access to HIV counseling and testing (HCT) among the youths in Gulu (Uganda). Afr J Infect Dis. 2012;6(1):12-20.

22. Nakimuli-Mpungu E, Alderman S, Kinyanda E, Allden K, Betancourt TS, Alderman JS, et al. Implementation and scale-up of psycho-trauma centers in a post-conflict area: a case study of a private-public Partnership in Northern Uganda. PLoS Med. 2013;10(4):e1001427.

23. O'Laughlin KN, Kasozi J, Walensky RP, Parker RA, Faustin ZM, Doraiswamy S, et al. Clinic-based routine voluntary HIV testing in a refugee settlement in Uganda. J Acquir Immune Defic Syndr. 2014;67(4):409-13.

24. AMICAALL, Comprehensive baseline survey on HIV/aids among young people (10-24 years) in KARAMOJA sub-region. 2016. Available at: http://www.amicaalluganda.org/wp-content/uploads/2017/05/AMICAALLBaseline-Survey-FINAL-WEB.pdf. Accessed on 4 July 2017.

25. Ministry of Health, MoH, Uganda AIDS Indicator survey (UAIS). 2011. Available at: http://health.go.ug/docs/UAIS_2011_REPORT.pdf. Accessed on 30 July 2017. 
26. UNICEF, Adolescent girls vulnerability index: guiding strategic Investment in Uganda. 2013.Available at: https://www.unicef.org/uganda/PGY.AGI_ Uganda_2013.pdf. Accessed 27 June 2017.

27. UNICEF, UNICEF annual report. 2013.Available at: https://www.unicef.org/ publications/files/UNICEF_Annual_Report_2013_web_26_June_2014.pdf. Accessed on 18 July 2017.

28. Bennett S, Woods T, Liyanage WM, Smith DL. Simplified general method for cluster-sample surveys of health in developing countries. World Health Stat Q. 1991:44(3):98-106

29. Carey MP, Schroder KE. Development and psychometric evaluation of the brief HIV knowledge questionnaire. AIDS Educ Prev. 2002;14:172-82.

30. Thanavanh B, Harun-Or-Rashid M, Kasuya H, Sakamoto J. Knowledge, attitudes and practices regarding HIV/AIDS among male high school students in Lao People's Democratic Republic. J Int AIDS Soc. 2013;16(1):17387.

31. UNAIDS aidsinfo. HIV prevalence for young people. 2017, Available at: http://aidsinfo.unaids.org/. Accessed 28 Sept 2017.

32. Uganda Bureau of Statistics, Uganda demographic and health survey, Key indicators report 2016. Available at: health.go.ug/download/file/fid/1325. Accessed on 25 July 2017.

33. Ramirez-Avila L, Nixon K, Noubary F, Noubary F, Giddy J, Losina E, et al. Routine HIV testing in adolescents and young adults presenting to an outpatient Clinic in Durban, South Africa. PLoS One. 2012;7(9):e45507.

34. UNDP, The joint UN Programme of support on AIDS in Uganda: MPTF OFFICE GENERIC ANNUAL PROGRAMME NARRATIVE PROGRESS REPORT 2016. Available at: mptf.undp.org/document/download/18012. Accessed on 10 Aug 2017.

35. Adebayo OW, Gonzalez-Guarda RM. Factors associated with HIV testing in youth in the United States: an integrative review. J Assoc Nurses AIDS Care. 2017;28(3):342-62.

36. Mutumba M, Musiime V, Tsai AC, Byaruhanda J, Kiweewa F, Bauermeister JA, et al. Disclosure of HIV status to perinatally infected adolescents in urban Uganda: a qualitative study on timing, process, and outcomes. J Assoc Nurses AIDS Care. 2015;26(4):472-84.

37. Inzaule SC, Hamers RL, Kityo C, Rinke de wit TF, Roura F. Long-term antiretroviral treatment adherence in HIV-infected adolescents and adults in Uganda: a qualitative study. PLoS One. 2016;11(11):e0167492.

38. Straub DM, Arrington-Sanders R, Harris DR, Willard N, Kapogiannis B, Emmanuel $\mathrm{P}$, et al. Correlates of HIV testing history among urban youth recruited through venue-based testing in 15 US cities. Sex Transm Dis. 2011;38(8):691-6.

39. Brima N, Burns F, Fakoya I, Kargbo B, Conteh S, Copas A. Factors associated with HIV prevalence and HIV testing in Sierra Leone: findings from the 2008 demographic health survey. PLoS One. 2015;10(10):e0137055.

40. Caldeira KM, Singer BJ, O'grady KE, Vincent KB, Arria AM. HIV testing in recent college students: prevalence and correlates. AIDS Educ Prev. 2012;24(4):363-76.

41. Mkandawire P. Assessing factors associated with HIV testing among adolescents in Malawi. Global Public Health. 2017;12(7):927-40.

42. Bumgarner KF, Pharr J, Buttner M, Ezeanolue E. Interventions that increase the intention to seek voluntary HIV testing in young people: a review. AIDS Care. 2017:29(3):365-71.

43. Schnall R, Rojas M, Travers J. Understanding HIV testing behaviors of minority adolescents: a health behavior model analysis. J Assoc Nurses AIDS Care. 2015;26(3):246-58.

\section{Ready to submit your research? Choose BMC and benefit from:}

- fast, convenient online submission

- thorough peer review by experienced researchers in your field

- rapid publication on acceptance

- support for research data, including large and complex data types

- gold Open Access which fosters wider collaboration and increased citations

- maximum visibility for your research: over $100 \mathrm{M}$ website views per year

At BMC, research is always in progress.

Learn more biomedcentral.com/submissions 